tung durch zehn Flammen beträgt die Consumtion des Sauerstoffgases 17 Litres stündlich. Herr Gaudin schlägt auch die Anwendung seines sideralen Schiffslichts für die Beleuchtung der Eisenbahnen vor. (M.d.L.d.A. 1816.) G.

\title{
Verhinderung der Explosion des Schiesspulvers und Errichtung eines eleltrischen Telegraphen in Russland.
}

Die französische Akademie der Wissenschaften hat die Erfindung, dass man dem Schiesspulver die explodirende Kraft geben und nehmen kann, bekannt gemacht. Die Akademie hat die Versuche gesehen, es ist also kein Misstrauen mehr möglich. Pulvermagazine werden, wenn das vorgeschlagene Verfahren angewendet wird, Feuer fangen können und man wird so ruhig dabei sein, wie bei einem andern Brande. Das Verfahren ist so einfach, dass man sich wundert, warum derjenige, der das Pulver erfunden hat, nicht auch zugleich diess erfand. Urheber der Entdeckung ist ein sehr verdientes Mitglied der Akademie, der Artillerie-Officier Robert. Sein Vorschlag ist folgender: Man mische das Schiesspulver mit Salpeter oder Kohlenstaub, so wird man es durch keinen Versuch zum Detoniren bringen können. Es wird zwar vom Feuer ergriffen werden, aber nicht auflammen, sondern, wie Kalk, der gelöscht wird, unter Zischen zerfliessen. Um die Explosion wieder möglich zu machen, darf man nur ein Sieb anwenden, durch welches die fremden Stoffe leicht ausgeschieden werden können. Manipulirt man aber nicht mit körnigem, sondern mit zerstampftem Pulver, so muss man die Kohlentheilchen etwas stark wählen, dann geht das Pulver durch das Sieb, während die Kohle zuruickbleibt. Die Anwendung des gepulverten Bleierzes hat dasselbe genügende Resultat geliefert. In einem der neuesten Versuche hat man zwei Tönnchen mit Pulver, das auf solche Weise präparirt war, über einander gestellt, und das untere angezindet, und siehe da, in dem untern verglimmte das Pulver, wahrend das obere unversehrt blieb. Die Wärmeentwicklung war so gering, dass schon die Holzböden der Tönnchen, durch welche beide Pulvermengen getrennt wurden, das Umsichgreifen des Feuers verhindern konnten. Dieser letzte Versuch ist nicht von dem Erfinder selbst gemacht worden, sondern fand in Russland unter den Augen des Grossfürsten Michael statt. Die Entdeckung ist schon geraume Zeit 
alt, aber man hatte sie vergessen, und der Autor selbst sprach nicht mehr davon. Er sah ohne Zweifel, dass sie nicht nach Verdienst getwürdigt wurde. und überliess es der Zukunft, ihm Anerkennung zu verschaffen. Wie erstaunt muss der französische Akademiker gewesen sein, dieselbe zuerst in dem fernen Russland gefunden zu haben! Uebrigens kann er gewiss sein, dass sich die Russische Regierung nicht auf die Eruirung des wissenschaftlichen Factums beschranken, sondern seinen Vorschlag bald in allen Pulvermühlen und Magazinen in Ausfiuhrung bringen wird. Wir brauchen nur an den elektrischen Telegraphen zu erinnern, in Bezug auf welchen Russland ebenfalls dem übrigen Europa vorangegangen ist. Man hat mit demselben in Italien, Frankreich, England experimentirt, aber nur in Russland einen errichtet. Die Telegraphenlinie geht aus von dem Cabinette des Kaisers in Zarskoje-Selo und mündet im Hause des ersten Ministers in Petersburg. Die Communication soll mit bewunderungswiirdiger Deutlichkeit und Geschwindigkeit statt finden. Die Einrichtung ist so vollständig, dass das elektrische Fluidum sogar eine Glocke in Bewegung setzt, um den Anfang der Correspondenz anzuzeigen. (Mag. d. Lit. d. Ausl. 1814. 82.)

Vorstehende Mittheilung veranlasste mich, zu versuchen, ob auch die Schiessbaumwolle durch Kohle oder Salpeter ihre Entziindbarkeit einbuisse; ich fand indessen, dass diese nach dem Wälzen der Schiessbaumwolle in Salpeter oder Kohlenpulver sich nur um ein Geringes vermindert hatte.

G.

\section{Ammoniakgehalt der Atmosphäre.}

Es wird Veranlassung genommen, die von Graeger angestellten Versuche in gedachter Beziehung näher zu prüfen. Nach diesen sollten in 1,000000 Theilen der Luft 0,6148 Theile kohlensaures Ammoniak vorhanden sein. Bussy vermuthet, dass ein Irrthum statt gefunden habe, indem vielleicht die als Reagentien benutzte Salzsäure und auch das Chlorblei nicht völlig rein gewesen.

Bemerkung. Die Gegenwart des Ammoniaks in der Atmosphäre ist ubrigens schon bestätiget von Liebig, Brandes u. A. Vielleicht dürfte die salpetersaure Quecksilberoxydullösung auch hier nicht ausser Acht zu setzen und namentlich eine grössere Menge destillirten Wassers wiederholt mit der zu prüfenden almosphärischen Luft in Berührung zu bringen sein, um durch Erhitzen im pneu- 